\title{
SEGREGAÇÃO E FRAGMENTAÇÃO URBANA EM TERESINA-PI: Condomínios fechados e o adensamento da periferia
}

\author{
LEAL JUNIOR, Jose Hamilton \\ Centro Universitário Uninovafapi/Professor Mestre do Curso de Arquitetura e Urbanismo, Brasil, \\ josehamilton.arq@gmail.com
}

\section{RESUMO}

A mancha urbana de Teresina cresceu com problemas comuns às demais cidades brasileiras, mas apresenta aspectos específicos em função de suas características sócio-espaciais. Dentre os problemas urbanos existentes na cidade, a segregação e a fragmentação urbana têm trazido consequências perversas à maior parte da população, sendo um processo paralelo à ascensão dos condomínios fechados na América Latina. Esses empreendimentos imobiliários estão no centro das discussões sobre a necessidade e ausência de interação social entre diferentes classes assim como o impacto destes na malha urbana. Este trabalho analisou o processo de expansão urbana e as transformações ocorridas a partir do Centro Urbano de Teresina, de 1930 aos dias atuais, a partir dos Planos Urbanísticos e da introdução ou expansão de alguns elementos morfológicos envolvidos no processo.

Palavras-chave: segregação urbana, condomínios fechados, morfologia urbana.

\begin{abstract}
The urban spot of Teresina grew with problems common to other Brazilian cities, but presents specific aspects in function of its socio-spatial characteristics. Among the urban problems in the city, segregation and urban fragmentation have had perverse consequences for most of the population, a process parallel to the rise of gated communities in Latin America. These real estate ventures are at the center of discussions about the need and absence of social interaction between different classes as well as their impact on the urban fabric. This work analyzed the process of urban expansion and the transformations that occurred from the Urban Center of Teresina, from 1930 to the present day, from the Urban Plans and the introduction or expansion of some morphological elements involved in the process.
\end{abstract}

keywords: urban segregation, gated communities, urban morphology. 


\section{INTRODUÇÃO}

A compreensão do relacionamento entre os processos urbanos e os elementos morfológicos torna-se de fundamental importância para a gestão das cidades atuais, haja vista que já existe compreensão do relacionamento entre os mesmos e várias manifestações físicas dos fenômenos sociais. Destaca-se em meio a atual conjuntura urbana brasileira, pós Estatuto das Cidades, que mais do que a falta de planejamento, ou o mesmo desligado das realidades locais (realidade predominante durante a década de 1970), o Brasil contemporâneo sofre pela dificuldade em implantar de forma continuada, os planos já elaborados. Principalmente por questões políticas e prevalecimento de interesses privados.

Em Teresina, dados levantados a partir da década de 1970 clareiam como ocorreu o processo de concentração das camadas mais altas em quatro bairros limítrofes (Jockey, Fátima, Ilhotas e Ininga) consolidando ao longo dos anos um processo denominado por Villaça (1998) como segregação socioespacial. Com o processo de segregação outros fenômenos começam a se manifestar em meio ao tecido urbano, possivelmente relacionados a ela, por exemplo, o surgimento de um possível subcentro, conforme definição de Villaça (1991, p: 274) e consequente abandono do centro por uma determinada população.

Desde o início da década de 2000, duas formas de morar vêm se intensificando entre as classes média e alta em Teresina: os condomínios verticais, e os condomínios fechados horizontais, diferenciados entre si em relação à localização, o primeiro na zona leste de Teresina, já com grande desenvolvimento em infraestrutura e o segundo em locais periféricos, próximos aos limites da cidade, na margem de rodovias.

A literatura especializada afirma que o movimento de determinadas classes sociais direcionam também investimentos e até o próprio centro para suas "zonas de interesse" ficando a dúvida sobre o que origina este movimento de classes. Esta pesquisa busca analisar e expor os fatos, ao nível específico da cidade de Teresina, como se deu o relacionamento entre a infraestrutura urbana e o movimento das classes sociais ao longo de décadas de planejamento e expansão da malha urbana.

\section{QUEBRAS NO TECIDO SOCIAL}

\subsection{SEGREGAÇÃO URBANA}

No estudo dos processos urbanos que ocorrem na cidade capitalista, Correa (1995) acredita que os processos sociais criam funções e formas espaciais, ligadas fundamentalmente a acumulação de capital e reprodução social, que merecem ser analisadas. Dentre os processos espaciais e as suas respectivas formas o autor destaca:

a) Centralização e área central: formação de uma área central (densamente povoada e bem servida de infraestrutura e serviços, ocupada fundamentalmente pelos empreendimentos cujo lucro derivam da boa localização) e de uma zona periférica do centro ( zona mista, não tão verticalizada como o centro, habitado por pessoas de classe média e baixa que trabalham na zona, foco dos transportes inter-regionais;

b) Descentralização e os núcleos secundários: deriva dos fatores de repulsão das áreas centrais (alto preço da terra, congestionamentos e prejuízos com transportes, dificuldade para expansão física das empresas, restrições legais sobre o uso do solo) que levam empresas para áreas não centrais que apresentam atrativos, gerando núcleos secundários;

c) Coesão e áreas especializadas: também chamado de magnetismo funcional, é o processo que leva as atividades a se localizarem juntas;

d) Segregação e as áreas sociais: processo iniciado pela segregação residencial (concentração de tipos de população dentro de um lado do território), são áreas marcadas pela uniformidade em termo de conjunto de características (status socioeconômico, urbanização e etnia);. Para Villaça (1998) dentre os fenômenos manifestos no espaço urbano a segregação é o processo fundamental para compreensão da estrutura espacial intraurbana. Thibert e Osorio (2013) afirmam que a segregação manifesta-se em metrópoles da América Latina tanto em termos de segregação de etnia e grupos sociais quanto em termos de segregação de usos e funções dentro da cidade, sendo onipresente, mas heterogênea.

O planejamento estatal pode se tornar um dos "produtores" do espaço segregado através da utilização de instrumentos urbanísticos, no caso o zoneamento.

"Mais marcado que a Europa por desigualdades sociais, em larga medida associadas à problemática da discriminação étnica, os EUA viram prosperar a utilização do zoneamento como um meio de exclusão social de maneira particularmente intensa. (SOUZA, 2011, p:252)."

Dessa forma, para alcançar os objetivos a que se propõe este trabalho, mesmo sabendo da existência de diversas formas de segregação, o foco será mantido sobre a segregação sócio espacial e seus desdobramentos. 


\subsection{SEGREGAÇÃO SOCIOESPACIAL}

Para Villaça (1998, p: 147), em relação à segregação de classes sociais podem ser identificadas dois tipos: segregação voluntária e segregação involuntária.

A segregação voluntária ocorreria quando indivíduos, por sua própria vontade, buscam viver com outras pessoas de sua classe, cabe como exemplo a segregação de pessoas que optam por habitar condomínios fechados, vilas estudantis e alguns bairros planejados. Como afirmou Jacobs (2000), essas pessoas escolhem seus vizinhos, algo negativo para a formação de um meio urbano diversificado, essencial para dirimir preconceitos e conflitos entre grupos distintos.

A segregação involuntária: ocorre quando o "indivíduo ou uma família" se veem obrigadas, pelas mais variadas forças, a morar num setor, ou deixar de morar num setor ou bairro da cidade. Notadamente, os atores que determinam a saída de determinados grupos são os promotores imobiliários e o Estado, que apesar de conhecer os benefícios do adensamento populacional e da implementação de justiça social, permanece cedendo a interesses individuais.

Para Villaça (1998), não existe correlação absoluta entre o preço da terra e o local de residência das pessoas de alta renda, haja vista que quanto menor o valor da terra, maior a possibilidade de lucro sobre a mesma.

Perez (2011) demonstra tal independência entre a localização das camadas de alta renda e o preço da terra quando analisa a ascensão de condomínios fechados para pessoas de alta renda em bairros historicamente de baixa renda na cidade de Santiago, Chile.

No Chile, assim como no Brasil, as políticas habitacionais locam os mais pobres nas áreas mais afastadas e deficientes de infraestrutura, onde a terra é mais barata.

Segundo Perez (2011) o mercado está colocando pessoas de média e alta renda em locais onde anteriormente, na década de 1980, foram colocadas pessoas de baixa renda, o autor ainda afirma que o deslocamento das classes sociais de alta renda para a periferia "pobre" tem relação com a abertura política Chilena que em vez do controle e regulação centralizadora do Estado, adotou um padrão de desenvolvimento e expansão urbano estruturado pela lógica do mercado. O setor imobiliário identificou maiores possibilidades de lucro em zonas periféricas, onde estavam localizados os bairros mais pobres, e consequentemente, como relaciona Villaça (1998, p:146) a terra com menor custo.

"Therefore, on a small scale, it is currently possible to find a wider spatial distribution of socially mixed neighborhoods than before, as a function of the aggressive colonization of poor sectors by private enclaves. (PEREZ, 2011, p. 2)"

A proximidade espacial entre classes sociais tão distintas põe em dúvida a existência ou não da segregação de classes, sendo assim alguns estudiosos chilenos viram a proximidade espacial existente entre os condomínios fechados e as comunidades pobres, como uma forma de integração social.

Villaça (1998, p: 142) define segregação socioespacial como "um processo segundo o qual diferentes classes ou camadas sociais tendem a se concentrar cada vez mais em diferentes regiões gerais ou conjuntos de bairros da metrópole".

Para Perez (2011, p:05) existem três dimensões deste fenômeno: concentração e homogeneidade (que ele caracteriza como objetivas) e percepção (que ele caracteriza como subjetiva). A concentração corresponde à tendência de certos grupos se concentrarem em certos bairros da cidade. A homogeneidade tem relação com a formação de bairros socialmente homogêneos e a percepção seria o sentimento e identificação da homogeneidade e concentração por parte dos residentes.

Concentração e homogeneidade são aspectos relacionados com a forma como as elites vêm se concentrando na América Latina (Perez, 2011, p:05), forma que o autor chama de cone, e identificadas como setor de círculo por Villaça (1998).

A presença dos setores de circulo nas metrópoles brasileiras, figura 1, tem relação com a necessidade de manter o acesso ao centro da cidade, com o grande desequilíbrio existente entre as classes sociais (que não permite o fechamento de uma coroa de círculo por parte da diminuta elite em torno das áreas centrais) e com o tamanho minoritário de determinadas atividades, a exemplo comércio e indústria (VILLAÇA, 1998, p: 153). 
CIDADES MÉDIAS E PEQUENAS

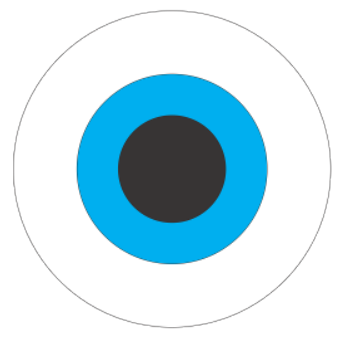

CENTRO
METRÓPOLES NA AMÉRICA LATINA

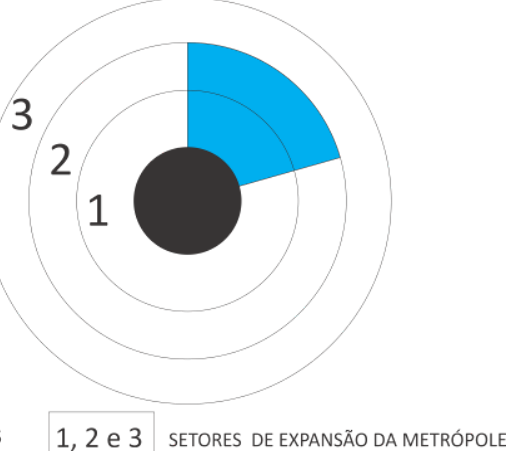

Figura 1: Modelo esquemático do crescimento radial em cidades pequenas e médias com base nas teorias de Villaça (1998) e Perez(2011).

Fonte: Jose Hamilton, 2013.

ESQUEMA DE KHOL

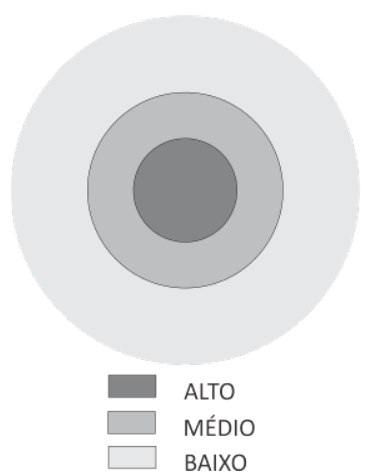

BAIXO
ESQUEMA DE BURGESS

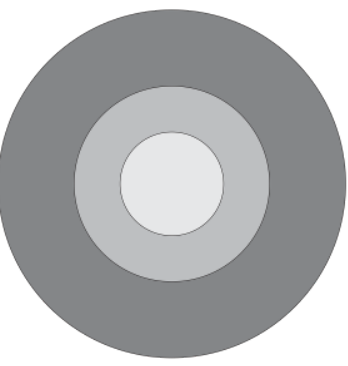

ESQUEMA DE HOYT

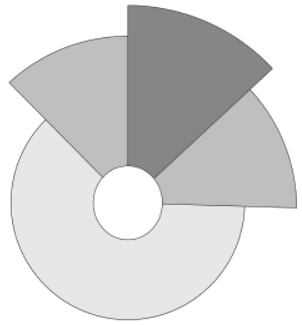

Figura 2: Modelos esquemáticos de segregação espacial apresentado por Correa (1995) com base em outros autores.

Fonte: Correa (1995), Modificado por Jose Hamilton, 2014. 
Teoricamente, o que vem ocorrendo em Santiago no Chile, deveria promover a proximidade geográfica entre grupos distintos e gerar a integração social, no entanto, Perez (2011) alerta sobre a restrição desse relacionamento a relações formais de emprego. É importante ressaltar que apesar de questionar a contribuição dessa proximidade encerrada por muros, Perez (2011) argumenta que a chegada de pessoas com melhor renda impulsionou a chegada de infraestrutura e serviços para áreas que mantinham grande deficiência, confirmando mais uma vez, o pensamento de Villaça (1998) e Harvey (1980), quando este diz que os serviços e a infraestrutura urbana são direcionados para o local onde habita as pessoas de alta renda.

"Qualquer intenção de entender os mecanismos geradores de desigualdades de renda deve, por isso, consistir em compreender o processo político que opera numa cidade." (HARVEY, 1980, p. 59)

A discussão sobre as consequências da proximidade entre classes distintas e geograficamente próximas, abre caminho para a apresentação de outro conceito: fragmentação social. Segundo

Thibert e Osorio (2013), o fenômeno da segregação é onipresente na América Latina, no entanto não é homogêneo, para os autores apesar da heterogeneidade na evolução espacial das aglomerações da América Latina, um padrão claro surge na literatura: as cidades na América Latina e suas metrópoles regionais estão se tornando mais mistas no nível macro e mais segregadas no nível micro.

\subsection{FRAGMENTAÇÃO URBANA}

A globalização conduz a um processo de dualização da sociedade que se caracteriza pela crescente polarização econômica entre diferentes classes (CHETRY, 2014; SOUZA, 2003). Vários autores somam esta polarização econômica que enriquece uma minoria, aumentando as desigualdades sociais, à história conturbada dos países da América Latina, que durante grande parte do século $\mathrm{XX}$, foram submetidos a governos ditatoriais e que juntamente com a abertura política do fim da década de 1980 tiveram uma desregulamentação que beneficiaria o mercado de terras, dando características latinas a um processo global, a ascensão dos condomínios fechados e a suburbanização das elites (PEREZ, 2011; THIBERT e OSORIO, 2013; SABATINI e CÁCERES, 2004; SANTOS, 2013;)

A suburbanização das elites é um fenômeno relativamente novo na América Latina, onde as famílias de alta renda, durante muito tempo, habitaram o centro e que segundo Villaça (1998), somente em meados do século XX afastaram-se para os setores de círculo, mantendo uma relação de simbiose com o centro, que acabava por deslocar-se em função das classes altas. Segundo o autor, nas grandes cidades, este sucumbiu quando do rompimento das elites com o centro. Nos Estados Unidos, Harvey (1980) descreve uma situação inversa em que as elites ocupam a periferia e as camadas mais populares o centro, devido à ausência de uma política habitacional para as classes de baixa renda, que dessa maneira eram obrigadas a habitar um centro estagnado e sem oportunidades de emprego.

Tanto Perez (2011), quanto Bustamante e Varela (2011) dentre outros autores relacionam a mudança no padrão de localização das moradias das famílias de alta renda na América Latina, com a vontade dos empreendedores imobiliários de obterem maiores lucros com a obtenção e venda de terrenos mais baratos, localizados em zonas periféricas, no modelo de urbanização difundido em todo o globo: os condomínios fechados.

Juntamente com a ascensão dos condomínios fechados, ganha força o emprego do termo fragmentação urbana, como uma alternativa para a análise dos fenômenos urbanos contemporâneos, e que muito se assemelha a segregação urbana devido à origem comum nas desigualdades sociais e seu reflexo no espaço físico. Tentando estabelecer a diferenciação entre o termo segregação e fragmentação, $\operatorname{CHETRY~}(2014$, p.65) analisa que em uma de suas acepções a fragmentação refere-se a um rompimento no espaço que seria impossível de reverter, seria a perda da qualidade de "integração" da cidade, enquanto que o termo segregação refere-se às desigualdades existentes, no entanto absorvidas pela malha urbana. Outro ponto destacado pelo autor é a análise da "descontinuidade espacial das diferenciações sociais", que denotam o interesse pelo elo entre a sociedade urbana e o espaço urbano como um objeto físico, presente nos estudos sobre fragmentação.

Segundo Janoschka e Glaske (2003) apud Santos (2013, p.64) existem diversos níveis analíticos de fragmentação urbana, seriam eles:

\section{a) Fragmentação físico-territorial;}

"segundo a qual há desintegração espacial do corpo urbano construído em unidades independentes, como a construção de áreas de acesso restrito em partes do tecido urbano (....."

b) Fragmentação social; 
"supressão de espaços públicos e organização da vida orientada para dentro, evitando o contato entre pessoas que se distinguem do seu estilo de vida."

c) Fragmentação Político territorial;

"ocorre nas urbanizações fechadas que se estendem a uma superfície tão extensa que os serviços comunitários e os meios de transportes são prejudicados."

Souza (2003) destaca que muito além de um agravamento das disparidades sociais e uma ruptura na malha urbana, nas grandes cidades brasileiras está ocorrendo uma "fragmentação do tecido sociopolítico-espacial" definida pelo autor como:

“(...) um processo que abrange tanto a formação de enclaves territoriais ilegais, controlados por grupos de criminosos, até o "autoenclausuramento" de uma parte crescente da classe média e das elites"(SOUZA, 2003, p.90).

Segundo o pensamento de Souza (2003) haveria um esfacelamento da cidade tanto ao nível do espaço físico, quanto das relações sociais e das divisões de poder.

Conforme alerta Chetry (2014), devido à abrangência e imprecisão do termo fragmentação, é importante esclarecer que neste trabalho a diferença entre segregação urbana, que seria um processo construído historicamente em que a maior parte de uma determinada classe social, habita bairros dispostos de forma a criar "um conjunto de bairros" dentro da cidade e fragmentação urbana, que é o surgimento de pequenas unidades de pobreza e riqueza geograficamente próximas, mas que não interagem socialmente baseiam-se nos conceitos difundidos por Villaça (1998) e Thibert e Osorio (2013), respectivamente.

\subsection{CONDOMÍNIOS FECHADOS: NOVAS FORMAS DE EXPANSÃO URBANA}

Em busca de segurança e status, a população de classe média e alta tem contribuído para a emergência dos condomínios fechados, gated communities, ao redor do mundo. Normalmente localizam-se em zonas periféricas, e mais recentemente próximos à comunidades de baixa renda, transformando o território tanto fisicamente quanto politicamente (Thibert e Osorio ,2013).

A explicação predominante entre os teóricos dos anos 80 é que o aumento dos condomínios fechados está diretamente relacionado ao aumento da insegurança urbana. Para Villaça (1998) independentemente do momento econômico ou da intensidade do sentimento de insegurança que paira sobre a vida urbana, sempre que há uma aproximação entre a classe social baixa e a alta, a última ergue barreiras físicas.

Os condomínios fechados mantêm algumas característica em comum ao redor do mundo, sendo algumas delas ligadas ao consumo e outras ao empreendimento. (SABATINI et AL (2004); PEREZ, 2011; THIBERT e OSORIO, 2013)

Primeiramente, as preocupações das classes mais abastadas quando procuram os condomínios fechados podem ser resumidas em: exclusividade, segurança, status e estilo de vida. São estas as qualidades que devem ser inerentes a estes empreendimentos (THIBERT e OSORIO, 2013). Outro ponto em comum entre esses empreendimentos é a escolha da localização, normalmente em áreas periféricas com pouca infraestrutura, próximas ou até mesmo fora do limite do perímetro urbano, área até então reservada para as camadas mais populares. Dessa forma acontece, vez por outra, o "encontro" entre classes sociais distintas, classe média alta, dentro dos muros e classe média baixa, fora deles. O que põe alguns teóricos a discutir, se existe segregação ou mesmo integração social. Com base em constatações de diversos pesquisadores Thibert e Osorio (2013) alertam que as cidades da América Latina estão se tornando mais diversificadas socialmente na escala do bairro, no entanto, mais fragmentados no nível do quarteirão e da rua.

\section{TERESINA: PROCESSO DE EXPANSÃO TERRITORIAL}

A cidade de Teresina, primeira cidade planejada do Brasil, foi fundada em 1852 para ser a nova capital do Piauí, às margens do Rio Parnaíba com a expectativa de que a navegabilidade do Rio pudesse trazer desenvolvimento econômico político e social para o Estado, o que não ocorreu. (SANTOS e KRUEL, 2009). Somente a partir da década de 1950, após a construção da Ponte Juscelino Kubitschek sobre o rio Poti e de um hipódromo na margem leste do rio, teve início a expansão da mancha urbana para a zona leste da cidade (LIMA, 2002). Paralelamente houve um movimento nacional para a construção de moradias para a classe trabalhadora que refletiu-se em Teresina com a expansão da Zona Sul.

Segundo a estimativa do Instituto Brasileiro de Geografia e Estatística (IBGE) no ano de 2016, Teresina possuia 847.430 habitantes, já a cidade de Timon, Maranhão, separada da cidade de Teresina somente pelo Rio Parnaíba possuía 166.295 pessoas. 


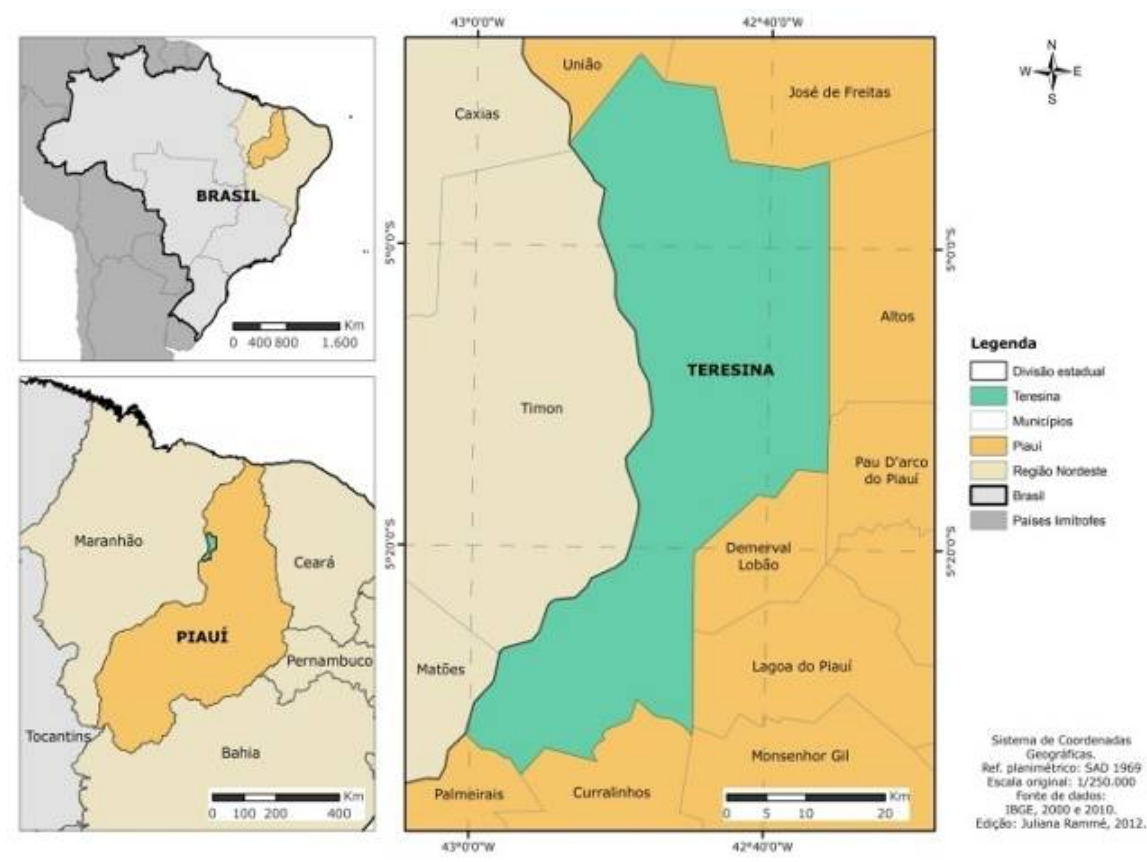

Figura 3: Mapa de Localização do Município de Teresina-Pi

Fonte: IBGE, 2000 e 2010. Edição: Juliana Rammé, 2012.

Segundo dados do Plano Diretor de Mobilidade Urbana de Teresina (2008, p:17), entre Teresina e Timon são feitas por dia 268.991 viagens, o que demonstra que as relações entre estes dois municípios vai muito além da proximidade física. Portanto, deve-se considerar, a nível de planejamento, o território timonense como uma extensão do teresinense.

Atualmente a cidade de Teresina convive com um centro com problemas de trânsito, principalmente pela saturação da Avenida Frei Serafim, principal eixo viário de ligação entre zona Leste e o Centro. Outro problema é a ausência de residências e de atrativos noturnos que ocasiona durante a noite, o seu esvaziamento, criando um ambiente propício para marginais. Além disso, muitos edifícios históricos do início da cidade estão sendo derrubados para abrigar estacionamentos, desfigurando seu patrimônio cultural e histórico.

Para Villaça (1998) a decadência dos centros urbanos das metrópoles brasileiras tem relação com o abandono do mesmo pelas classes altas, e o consequente deslocamento de vários serviços que eram exclusivos do centro para uma aproximação entre o setor de concentração das elites, criando um subcentro. Em Teresina pode-se considerar a existência de um subcentro na Zona Leste, local onde hoje se encontram os dois Shoppings da cidade e também um grande número de edifícios comerciais, promovendo uma diversidade de serviços que caracterizam o subcentro.

\subsection{A DINÂMICA DO TECIDO URBANO TERESINENSE}

A figura 4 demonstra que desde a década de 1960 existe uma movimentação para ocupação da Zona Leste de Teresina por parte das camadas de alta renda. Esta figura foi feita com base no mapa de zoneamento espontâneo retirado do Plano Local de Desenvolvimento Integrado de 1970 (PDLI, 1970), e demonstra uma tendência de ocupação do bairro de Fátima por residências de alta renda (mancha amarela) já naquele período. Percebe-se ainda uma intensa ocupação do centro da cidade por residências de classe média, sobrepondo-se a atividade comercial grossista que, segundo a figura, concentrava-se na borda do rio Parnaíba. A figura não faz referência ao comercio varejista que atualmente é a principal atividade desenvolvida naquela área ou ao Polo de Saúde que nos dias atuais ocupa todo o sudeste do centro. 

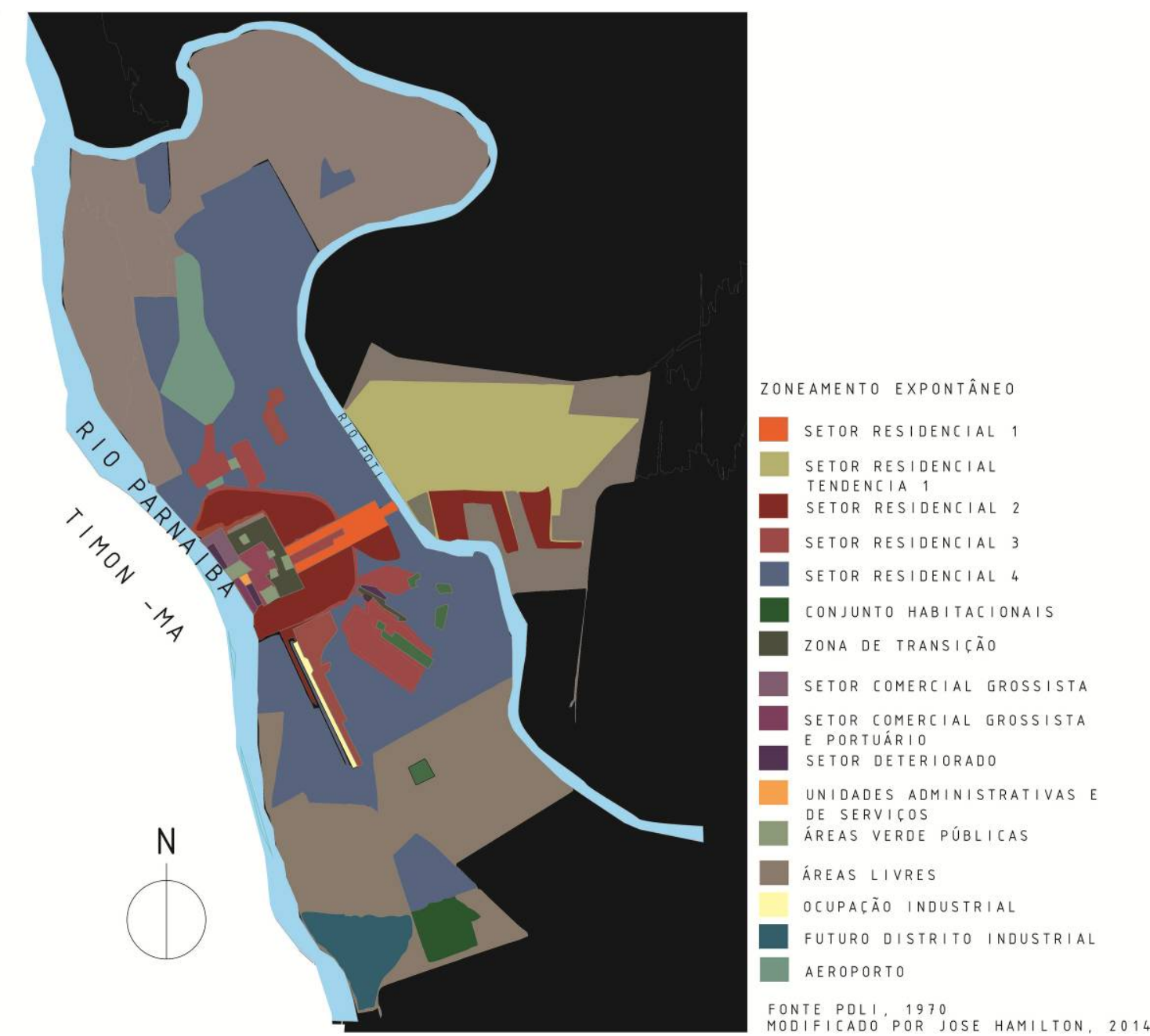

Figura 4 : Zoneamento Espontâneo presente em Teresina em 1969 Fonte: Teresina (1969), adaptado por Jose Hamilton, 2014.

Ainda explorando a imagem acima, percebe-se a localização de conjuntos habitacionais (mancha verde) no meio de áreas livres (neste caso específico áreas sem densidade de edificações). O mesmo ocorre com partes do setor residencial 4 (residências de baixa renda) que também ocupam áreas distantes do centro, apesar da grande quantidade de terrenos ociosos.

Quando analisamos a Planta de Valores dos Terrenos Urbanos (Figura 5) presente no mesmo documento, pode-se perceber que os terrenos mais caros eram ocupados (como já era esperado) pelas residências de alto padrão (residencial 1). Ocupando o segundo lugar em valorização estão os terrenos situados ao sul do centro, que possuíam uma densidade demográfica maior e eram munidos de infraestrutura, conforme figura 6. No entanto, não se justifica existência de considerável infraestrutura em bairros que, até então, possuíam pequena densidade demográfica quando comparada com vários outros bairros que eram mal servidos de serviços públicos, o que se refletia no valor da terra urbana (a exemplo da Figura 7 ).

É perceptível a existência de um banco de terras na zona leste, onde bairros sem expressão demográfica recebiam investimentos que os valorizavam, surgindo a tendência de residencial tipo 1 , conforme descrito na figura anterior. A tendência residencial 01 tornou-se realidade, e atualmente, esta zona concentra grande parte da população de alta renda do município, e segundo Teresina (2006) também possui os terrenos mais valorizados, assim como o Centro. 


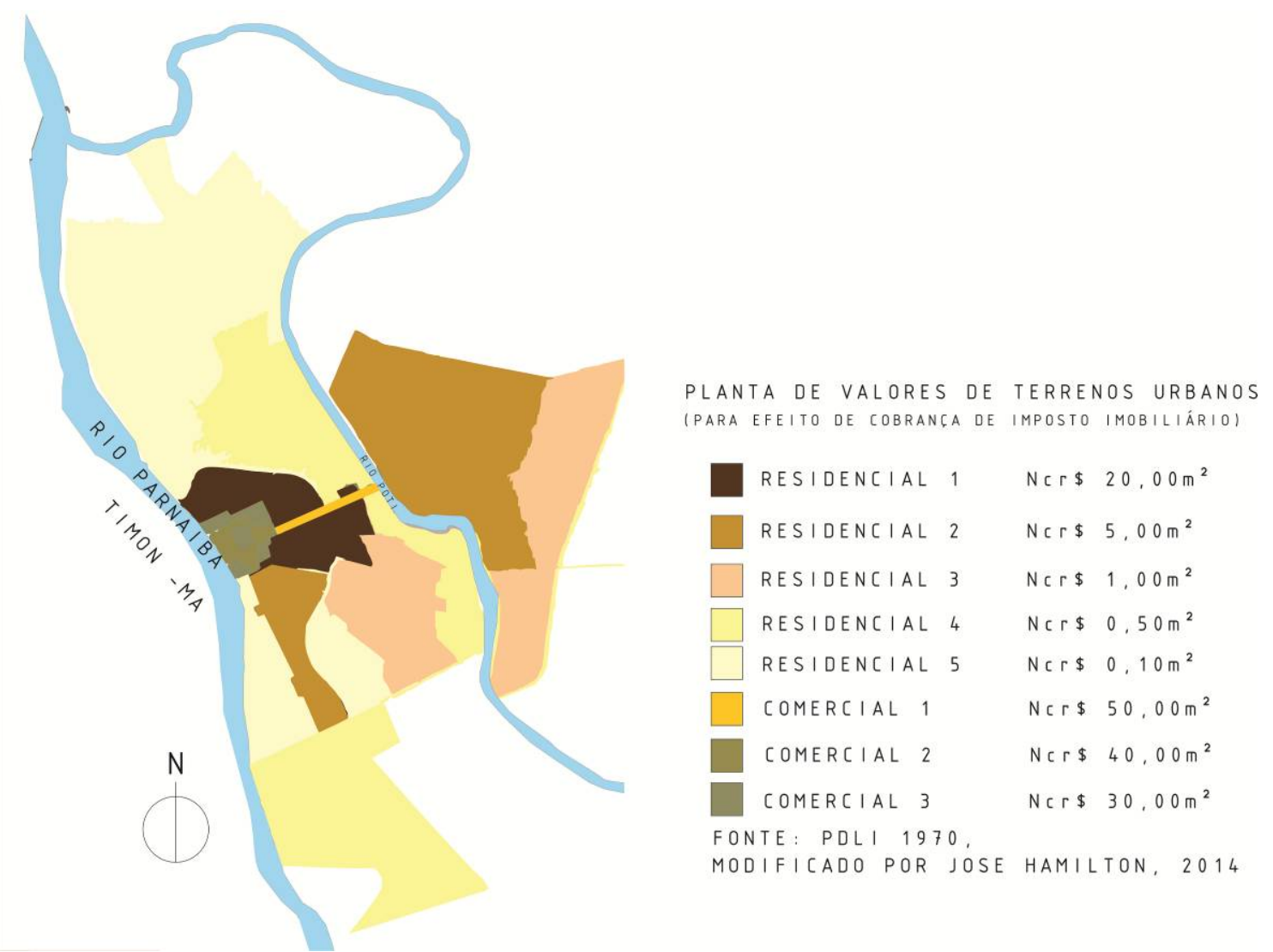

Figura 5 : Planta Valores de Terrenos Urbanos de Teresina em 1969 Fonte: Teresina (1969), modificado por Jose Hamilton, 2014.

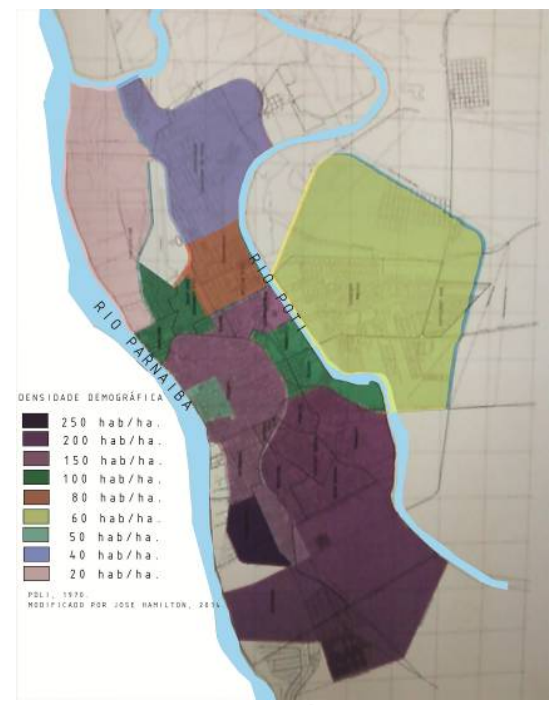

Figura 6: Densidade Demográfica por Bairros em 1969 Fonte: Teresina (1969), modificado por Jose Hamilton, 2014.

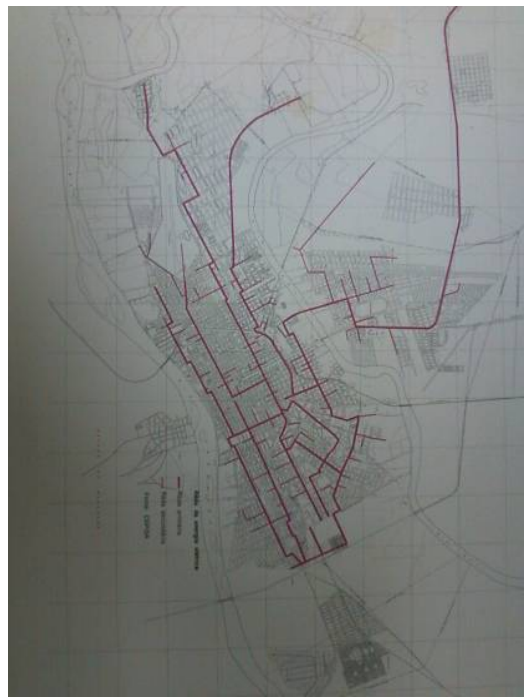

Figura 7: Rede de energia elétrica em Teresina em 1969

Fonte: Teresina (1969).

A análise das figuras acima demonstra que, no caso de Teresina, a formação do setor em que atualmente predominam as residências das pessoas com alta renda tem relação com a possibilidade de levar investimentos e a infraestrutura básica necessária a manutenção do padrão de vida destas populações. É possível concluir que as dificuldades de deslocamento desses serviços naquele período, fizeram com que as populações de alta renda se movimentassem para fora, no entanto, para proximidades do centro urbano. Em paralelo, conclui-se que atualmente, as facilidades de locação e ampliação da infraestrutura existente, assim como a existência de vias que colaboram para uma mobilidade maior, permitem a população de classe média alta deslocar-se para zona mais distantes do centro. 


\subsection{TENDENDÊNCIAS AO ADENSAMENTO DA PERIFERIA}

Em meados da década de 2000, condomínios residenciais para estratos populacionais de alta renda, encerrados por muros e cercas, começaram a instalar-se nos limites do perímetro urbano, alguns fora do mesmo, com normativas urbanas próprias, muitos com traçados diferenciados e soluções urbanas importadas de empreendimentos semelhantes de outras cidades, ver figura 8.
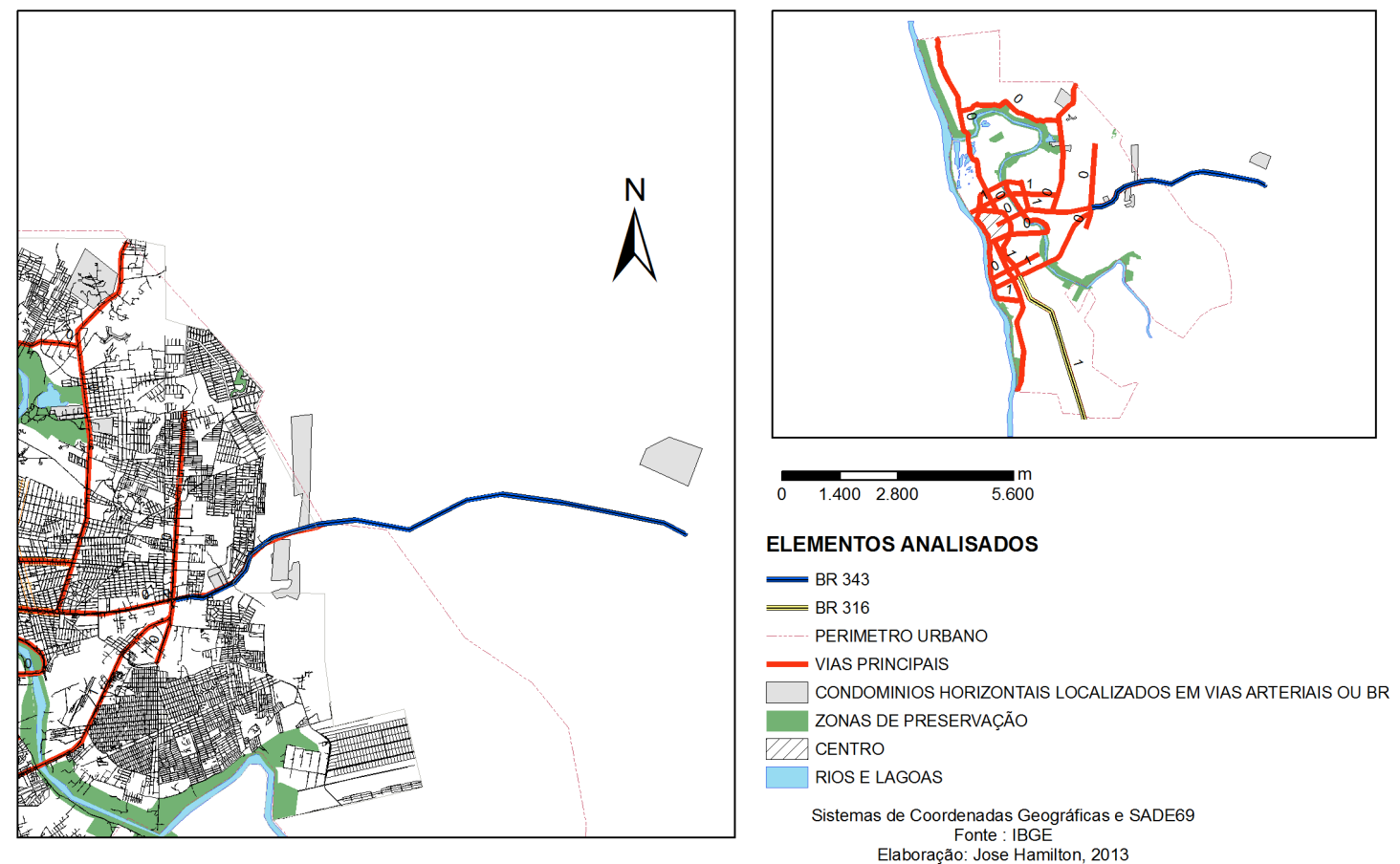

Figura 8: CONDOMINIOS FECHADOS HORIZONTAIS DE ALTA RENDA PRÓXIMOS ÀS VIAS ARTERIAIS E EXPRESSAS

Fonte: Jose Hamilton, 2013.

Já é unânime entre os planejadores urbanos que a retirada do tráfego pesado de dentro da cidade é importante tanto para desafogar o trânsito quanto para um melhor escoamento da produção. No caso específico de Teresina, é importante ressaltar que a capital é um elo entre o norte e o sul do estado, sendo prejudicial para a sociedade a instalação destes "bairros" nas bordas da rodovia, tendo esta como única via de acesso ao núcleo urbano onde se encontram as áreas de interesse (trabalho, educação e lazer).

Por outro lado, loteamentos populares construídos em parceria entre os governos municipal e federal também estão sendo instalados nas proximidades dos limites do perímetro, só que em zonas distantes da população de alta renda. Reinventando o processo de segregação entre classes, presente na cidade desde a sua implantação e fortalecido a partir da década de 1930.

A tabela 1 a seguir demonstra que a taxa de crescimento populacional em Teresina vem decrescendo ao longo dos anos, no entanto, analisando o aumento bruto, percebe-se que o aumento populacional ainda é expressivo, sugerindo a necessidade de um planejamento para a produção de moradias, principalmente quando analisamos a figura 09, que aponta os bairros da periferia com os maiores índice de crescimento populacional. 


\begin{tabular}{|l|l|l|c|}
\hline Ano & População & Taxa (\%) & $\begin{array}{l}\text { Aumento } \\
\text { Populacional Bruto }\end{array}$ \\
\hline 1940 & 63684 & - & 29.668 \\
\hline 1950 & 93.352 & 3,90 & 28.937 \\
\hline 1960 & 122.289 & 2,74 & 98.198 \\
\hline 1970 & 220.487 & 6,07 & 157.284 \\
\hline 1940 & 377.771 & 5,53 & 221.501 \\
\hline 1980 & 599.272 & 4,28 & 116.088 \\
\hline 2000 & 715.360 & 1,99 & 62.981 \\
\hline 2007 & 778.341 & 1,21 & 35.889 \\
\hline 2010 & 814.230 & 1,54 & \\
\hline
\end{tabular}

Tabela 1: Evolução das taxas de crescimento populacional das últimas décadas. Fonte: IBGE (2010), Teresina (2008).

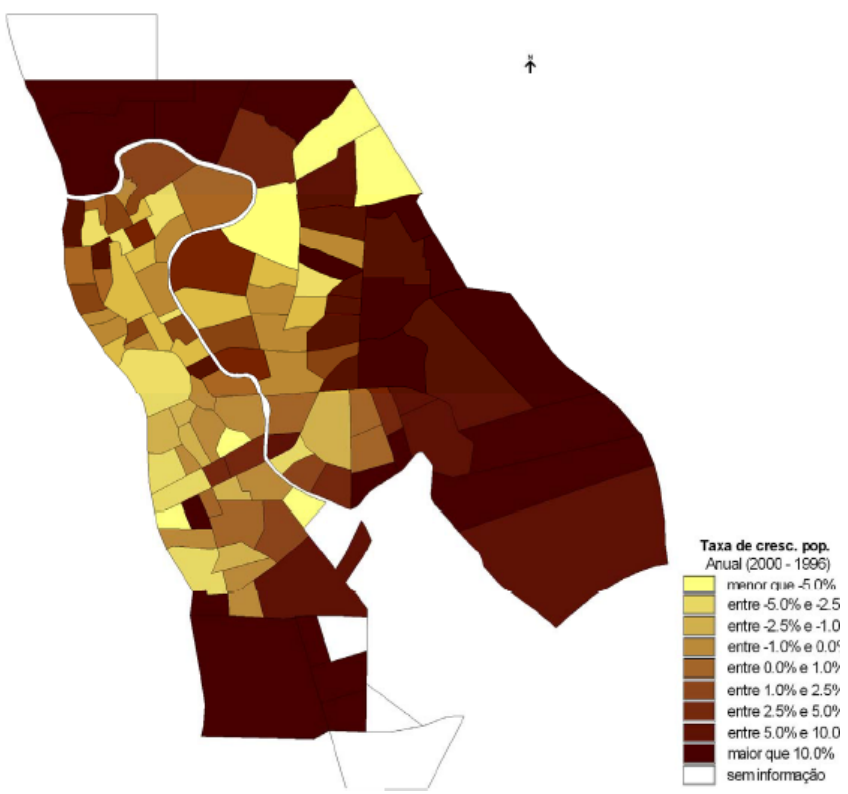

Figura 9: Taxa de Crescimento Populacional por bairro em 2000.

Fonte: Teresina $(2008$, p. 10)

A alta taxa de crescimento populacional concentrada nos bairros periféricos, mostrada na figura 9 , tem a ver com a instalação dos novos loteamentos populares, uma receita antiga já criticada no Plano de Desenvolvimento Local Integrado de 1969 que reconhece que a construção do Conjunto Parque Piauí, inaugurado em 1966, distando $7 \mathrm{~km}$ do Centro e sem núcleos de absorção de mão de obra no entorno, prejudicou toda aquela população que, além da baixa renda, tinha gastos expressivos com o deslocamento (TERESINA, 1969, p:50). O mesmo acontece nos dias atuais, haja vista que segundo Teresina (2008, p:107) a maior oferta de empregos encontra-se nas proximidades do Bairro Centro, conforme figura 10.

A expansão da mancha urbana da cidade, assim como seu adensamento é uma resposta às demandas socioespaciais que surgem em paralelo ao crescimento urbano.

\subsection{O MOVIMENTO DAS DIFERENTES CLASSES NA DÉCADA DE 2000.}

Segundo Villaça (1998) a segregação é fruto de uma luta entre diferentes classes por uma melhor localização. Quando o esquema do sistema viário de Teresina é colocado lado a lado com a figura desenvolvida pelo pesquisador Reis Filho (2012) com base nos dados do Censo 2010, pode-se visualizar com mais clareza como se deu o processo de segregação e como estes têm relação com determinados elementos morfológicos. Ao analisar a figura 10 percebe-se que a UFPI, foi "envolvida" pela população de Alta Renda , concentrando em seu entorno a maior parte desta população. Somado a isso, estes bairros (Jockey e Fátima) possuem ótima acessibilidade com quatro vias arteriais e como consequência, os terrenos mais caros da cidade. Em 
paralelo, o bairro onde está localizado o Aeroporto Petrônio Portela não valorizou na mesma proporção, apesar da proximidade do Centro e da grande quantidade de vias coletoras.

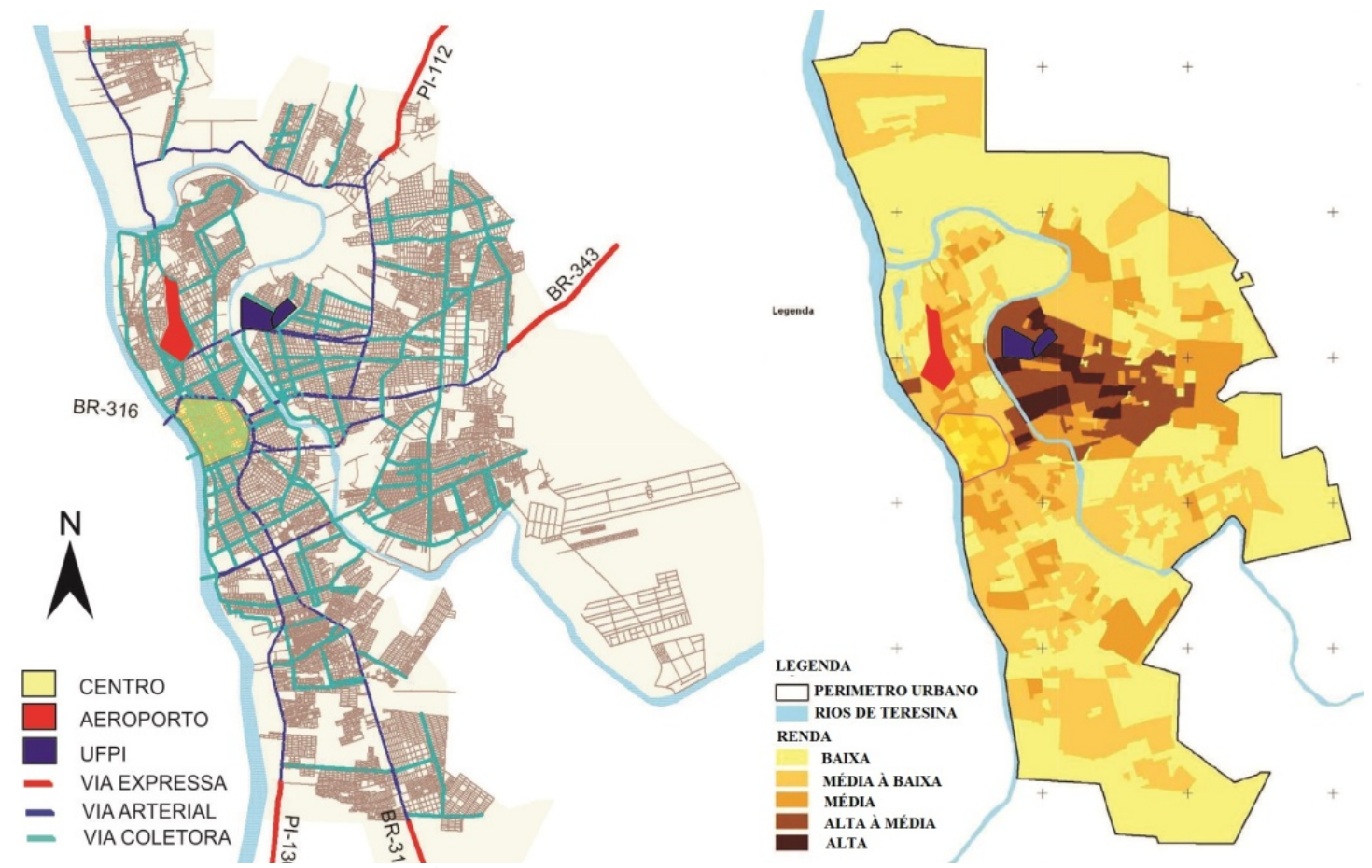

Figura 1: Distribuição da Malha Viária e Distribuição de Renda.

Fonte: Teresina, 2005 e REIS FILHO, 2012. Modificado por Jose Hamilton, 2013

transformações estruturais no espaço da cidade de Teresina, advindas da expansão da mancha urbana, sugerem que as diferenciações morfológicas do espaço urbano, principalmente decorrentes das intervenções de grande porte para construção de equipamentos correspondem a diferenciações na localização de distintos grupos sociais, caracterizando uma segregação que pode ser entendida de duas maneiras: a autossegregação (dos de maior renda) e a imposta (dos de menor renda).

"(...) a atividade de qualquer elemento em um sistema urbano pode gerar certos efeitos sem preço e talvez não monetários sobre outros elementos no sistema." (HARVEY, 1980, p.46)

As questões levantadas ao longo da pesquisa quando transformadas em gráfico na tabela 2, demonstram que a configuração inicial da cidade de Teresina assemelha-se ao modelo de Khol apresentado por Correa (1995). Após a segunda metade da década de 1970 percebe-se uma tendência à formação de um setor de círculo constituído por alguns bairros da zona leste da cidade, formados em sua maioria por pessoas de renda media a alta assemelhando-se ao modelo de setores de círculo, que segundo Villaça (1998) é uma característica das grandes cidades brasileiras. 


\begin{tabular}{|c|c|c|c|}
\hline 高 & 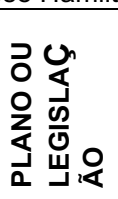 & $\begin{array}{l}\text { PRINCIPAIS } \\
\text { DESDOBRAMENTOS }\end{array}$ & $\begin{array}{l}\text { DITRIBUIÇÃO DE CLASSES SOCIAIS NO } \\
\text { ESPAÇO URBANO DE TERESINA DE ACORDO } \\
\text { COM A RENDA. }\end{array}$ \\
\hline 1852 & 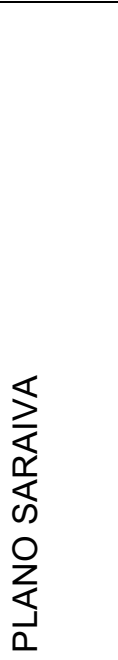 & $\begin{array}{lr}\text { Definição } & \text { da } \\
\text { localização } & \text { e } \\
\text { implantação } & \text { de } \\
\text { Teresina, } & \text { com } \\
\text { estabelecimento } & \text { de } \\
\text { um traçado } & \text { tipo } \\
\text { xadrez; } & \end{array}$ & TERESI \\
\hline 1939 & 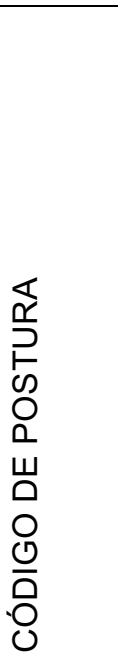 & $\begin{array}{l}\text { Proibição de } \\
\text { construção em taipa } \\
\text { e palha no perímetro } \\
\text { urbano; } \\
\text { Estipulação de } \\
\text { Gabarito mínimo } \\
\text { para a Avenida Frei } \\
\text { Serafim, então } \\
\text { Avenida Getúlio } \\
\text { Vargas; }\end{array}$ & $\begin{array}{c}\text { TERESINA } 1940 \\
\text { ALTA RENDA } \\
\text { MEDIA RENDA } \\
\square \text { BAIXA RENDA } \\
\square\end{array}$ \\
\hline 1969 & $\overline{\bar{\partial}}$ & $\begin{array}{l}\text { Criação de um anel } \\
\text { viário ao redor do } \\
\text { Centro da Cidade } \\
\text { com ligação para a } \\
\text { zona sul (Avenida } \\
\text { Miguel Rosa e Barão } \\
\text { de Gurguéia); }\end{array}$ & \\
\hline 1976 & $\underline{\underline{\underline{a}}}$ & $\begin{array}{l}\text { Estabelecimento de } \\
\text { um Zoneamento e } \\
\text { Legislação Urbana; }\end{array}$ & $\begin{array}{l}\text { TEREINA 1969 } \\
\text { BLAA RENDA } \\
\text { BAIXARENA } \\
\text { MEDIA RENDA } \\
\text { COMERCIO }\end{array}$ \\
\hline
\end{tabular}




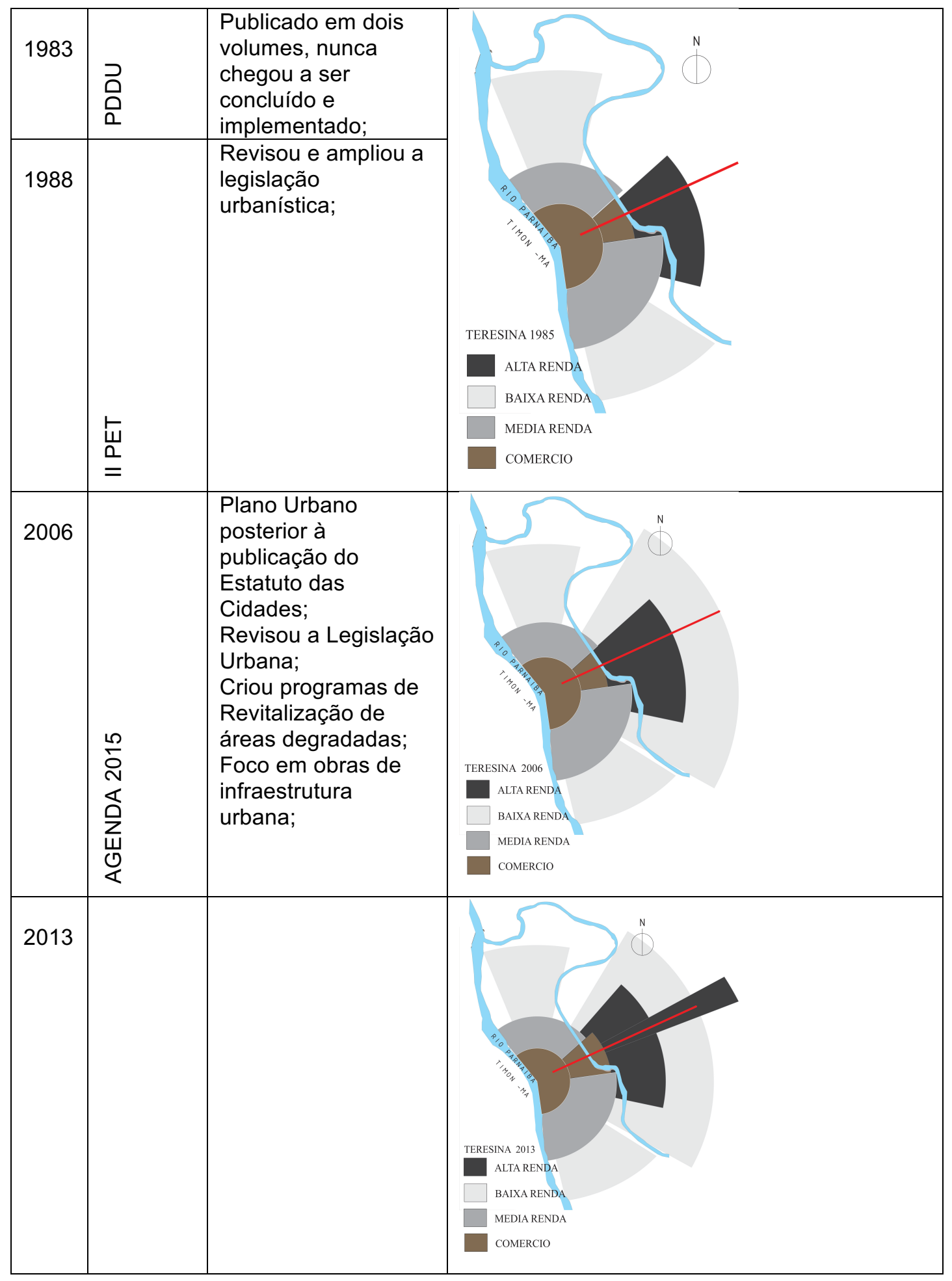

\section{CONSIDERAÇÕES FINAIS}

Com base nos conceitos apresentados anteriormente sobre segregação socioespacial e fragmentação urbana, e conforme análise dos dados que demonstram a evolução histórica da mancha urbana na cidade de Teresina, assim como a movimentação e tendência de movimentação das camadas de alta renda, pode-se sugerir que o processo de expansão de Teresina se assemelha em alguns pontos aos das metrópoles da América Latina como um todo, apresentando como característica a ascensão de condomínios fechados e a suburbanização das elites, que procuram lotes maiores, em terras mais baratas ( no caso específico de Teresina, mais barata para o empreendedor imobiliário e não necessariamente para o consumidor final). 
No entanto, difere do modelo global pela localização. Muitos empreendimentos ainda localizam-se dentro do perímetro urbano, enquanto que nas metrópoles estudadas, estes foram colocados na zona rural, ou em cidades menores, no entanto próximas.

Nota-se que na busca por uma melhor localização e proximidade ao centro da cidade, onde até pouco tempo estavam concentrados os principais serviços, a zona leste de Teresina consolidou-se como área de interesse dos promotores imobiliários. Ao tempo que a ocupação da zona sul, onde foram instalados os grandes loteamentos populares da década de 1960 propiciou a rápida urbanização daquela área, favorecendo economicamente os proprietários dos vazios urbanos existentes entre estes loteamentos e o Centro.

Ao implantar os loteamentos populares em zonas de expansão urbana, o Estado tornou-se um dos principais atores no processo de segregação urbana presente na cidade de Teresina. Grandes deslocamentos, quando não planejados e dotados de infraestrutura adequada são ruins para a sustentabilidade urbana, principalmente quando somados à concentração das atividades em determinada região do território provocando o congestionamento das vias arteriais, uma consequência da segregação Centro-Periferia.

\section{BIBLIOGRAFIA}

\section{Obra completa:}

CORRÊA, R. L (1995). O Espaço Urbano. 3. ed. São Paulo: Ática. p. 1-13.

HARVEY, D.(1980). Justiça social e a cidade. São Paulo: Hucitec.

SANTOS, Gervásio; KRUEL, Kenard(2009). História do Piauí.Teresina: Zodíaco.

SOUSA, M (2011). Mudar a Cidade: uma introdução Crítica ao Planejamento e à Gestão Urbanas. Bertand Brasil.

TERESINA (1969). Plano de Desenvolvimento Local Integrado de Teresina. Teresina: COPLAN.

TERESINA(2008). Plano Diretor de Transporte e Mobilidade Urbana de Teresina. Teresina: VILLAÇA, F(1998). Espaço Intra-Urbano no Brasil. São Paulo: Studio Nobel: FAPESP: Lincoln Institute.

\section{Revistas:}

PEREZ, M. A. (2011). The Emergence of Gated Communities in the Poor Periphery: Reflections on the New Urban Segregation and Social Integration in Santiago, Chile1. Berkeley Planning Journal, 24. Retrieved from http://link.periodicos.capes.gov.br/sfxlcl41?ctx_ver=Z39.88-2004\&ctx_enc=info:ofi/enc:UTF-8\&ctx_tim=201401-17T07\%3A23\%3A46IST\&url ver=Z39.88-

2004\&url_ctx_fmt=infofi/fmt:kev:mtx:ctx\&rfr_id=info:sid/primo.exlibrisgroup.com:primo3-Article-

scopus\&rft_val_fmt=info:ofi/fmt:kev:mtx:article\&rft.genre=article\&rft.atitle=The emergence of gated communities in the poor periphery: Reflections on the new urban segregation and social integration in Santiago\%2C Chile\&rft.jtitle=Berkeley Planning Journal\&rft.bt

Thibert, J., \& Osorio, G. A (2013). Urban Segregation and Metropolitics in Latin America: The Case of

Bogotá , Colombia. International Journal of Urban and Regional Research, (2009), 25, 2013.

doi:10.1111/1468-2427.12021

LIMA, I. M. de M. F(2002). Teresina: Urbanização e Meio Ambiente. Scientia et Spes. Teresina, ano 1, n. 2, p. 181-206.

\section{Legislação:}

TERESINA (2006). Lei Complementar No 3606 de dezembro de 2006. Código Tributário do Município de Teresina. Teresina, PI.

Fontes Eletrônicas:

IBGE. Censo 2010. IBGE. 2010. Disponível em; <http://censo2010.ibge.gov.br/>. Acesso em 23/12/2012. 